\title{
Interpreting postmortem drug analysis and redistribution in determining cause of death: a review
}

\section{Michael Kennedy}

Department of Clinical Pharmacology \& Toxicology, St Vincent's Hospital, University of New South Wales, Sydney, NSW, Australia
Correspondence: Michael Kennedy Level 4, 22 Darley Road, Manly 2095, Sydney, NSW, Australia

Tel +6I 299778265

Fax +6I 299774426

Email drmkenn@ozemail.com.au
This article was published in the following Dove Press journal:

Pathology and Laboratory Medicine International

3 August 2015

Number of times this article has been viewed

\begin{abstract}
Multiple interacting factors alter the measured concentration of almost all drugs after death. The ratio of centrally to peripherally collected samples provides an indication of this redistribution. At present, there are no reliable markers from which to accurately predict how much an individual drug has redistributed. Knowledge of antemortem factors is essential for the interpretation of the effects of any measured drug or toxin.
\end{abstract}

Keywords: postmortem drugs, drug redistribution

\section{Introduction}

Correct interpretation of postmortem drug concentrations is becoming increasingly important in forensic pharmacology and as an adjunct to clinical toxicology. The finding of drugs in a dead body can raise important questions - and may sometimes provide immediate answers - about cause of death and antemortem events. This in itself is not new. Postmortem assaying of drugs and toxic agents commenced in the midnineteenth century with chemical analysis being used to detect arsenic and antimony. At the time, this new technology resulted in some spectacular murder convictions that would have previously gone undetected. ${ }^{1,2}$ Technology today is of course far superior to the classical quantitative methods of 150 years ago, and detecting a drug in a dead body is only the first step in a long and sophisticated process of measurement and interpretation of drug concentrations. Nevertheless, McBay's summation of the process made in 1973 is still highly relevant: "In the absence of an autopsy or an enlightening medical history, it is difficult to determine how the amount of a specific poison in a person might be interpreted". ${ }^{3}$

Coming to the right conclusion about levels of pharmacological agents found after death is important. Various interested parties such as relatives of the deceased, clinical review processes, and judicial bodies receiving the results will act on these conclusions. The case of the Dr Harold Shipman, now estimated to have murdered 220 patients during his practicing life, serves as an example of getting it right. Vital evidence resulting in his conviction and subsequent imprisonment for murder was drug analysis and interpretation of the morphine concentrations found in nine exhumed bodies. ${ }^{4}$ Similarly, not reaching a wrong conclusion about levels of pharmacological agents found after death is essential to avoid gross miscarriages of justice. ${ }^{5}$

Most analytical work is performed by mass spectroscopy with subsequent ability to interpret very low concentrations of a larger number of drugs. The databases have grown considerably, and these advances have resulted in a number of areas relevant to 
forensic science. The overlap between "therapeutic", "toxic", and "lethal" concentrations has largely made these terms obsolete. ${ }^{6}$ The mechanisms and predictions of drugs that alter their concentrations after death is now better understood.

The concentrations of most drugs alter after death as a result of numerous mechanisms. These and other factors identified as changing the concentration of a drug postmortem are presented in Table 1.

\section{Evidence base}

The largest database of pharmacodynamic and pharmacokinetic parameters of most drugs is based on live subjects, most of whom are normal healthy volunteers. Correlations between plasma concentrations and therapeutic responses and toxicity have been obtained from patients and always need to be interpreted in relation to the individual clinical case. As clinical use of any particular drug expands, a larger database becomes established. This in turn expands on earlier data.

The database for the living is considerably larger than what is established in the area of forensic pharmacology. Most data in this area, sometimes termed necropharmacology, have been obtained from samples obtained from forensic autopsies. Each month, there are additions to the world literature in the form of case reports or small series reporting drug concentrations in varieties of circumstances. There are a number of comprehensive tabulations of postmortem drug concentrations that are valuable sources of information. In 1990, Prouty and Anderson tabulated the concentrations of 69 drugs from numerous vascular sites and solid organs obtained from hundreds of individuals who died under various conditions. ${ }^{7}$ Druid and Holmgren's examination of 15,000 samples, collected from medico-legal autopsies conducted in

Table I Factors affecting drug concentrations reported after death

I. Circumstances of death
2. Time since death
3. Alteration of the body for example by embalming or putrefaction
4. Position of the body during transport
5. Site of sample collection
6. Method of collection
7. Preservation of sample
8. Security of sample (legal cases)
9. Red blood cell/plasma partition
10. Chemical stability of sample after collection
11. Postmortem metabolism/chemical instability of drug
12. Bacterial metabolism of drugs
13. Postmortem drug synthesis
14. Drug redistribution
15. Analytical issues related to tissue samples

six laboratories in Sweden between 1992 and 1995, remains one of the most comprehensive retrospective reports. The authors tabulated the femoral concentrations of 83 drugs in relation to whether 1) the drug exclusively caused death on its own, 2) the drug caused death in combination with other substances, 3) the drug was associated with death due to other causes, and 4) a group was associated with suspected drug-related driving deaths. ${ }^{8}$ In 2012, Schulz et al compiled a comprehensive tabulation of almost 1,000 drugs and xenobiotics from various sources. ${ }^{9}$ The percentile distributions of postmortem concentrations of the top 25 drugs in Sweden serves as a guide to concentrations causing death and is useful in "flagging" a drug-related death. ${ }^{10}$

Baselt's Disposition of toxic drugs and chemicals in man is a standard reference text. It includes details of individual pharmacokinetic, binding properties and physicochemical and stability properties on a very large number of drugs and poisons. ${ }^{11}$ Repetto and Repetto compiled a reference table of 103 drugs with the proviso: "Although these data may be useful they should not be taken as absolute. Precaution must be taken when interpreting these values and relating them to a particular case."12 In other words, each case is subject to its own characteristics. With increased analytical sophistication and ever-growing interest from clinical, media, and legal areas, the database is slowly increasing, but there remain large areas that still require extensive research.

Drug concentrations measured in deceased individuals will rarely be the same as they were at the time of death. This was not fully appreciated until the 1970s, at which time, Bailey and Shaw reported considerable variations in amitriptyline concentrations in various organs. ${ }^{13}$ Later, in a much referenced article, Jones and Pounder describe the considerable variations in the concentrations of imipramine, desipramine, diphenhydramine, codeine, and paracetamol at different sites within the body of a female aged 25 who had died as a result of the polydrug overdose. ${ }^{14}$ These differences in concentrations are not due to any single factor. In most cases, it is the sum of multiple factors combining to alter the concentration of a drug after death. The relative importance of these factors will differ considerably between an individual who dies almost immediately after receiving a single dose of a drug and one who is in a pharmacokinetic steady state with the drug at the time of death. The resulting changes are sometimes grouped together and named "postmortem redistribution". This term was coined by Pounder and Jones in 1987. In 1990, Pounder further described it as "toxicological nightmare". ${ }^{15}$ Both terms continue to be used to the present day. 
The relative contribution of the various processes presents an everyday challenge to scientists and clinicians interpreting the analytical results obtained from autopsy samples.

The considerable technical complexities associated with the processing and analysis of collected samples have been reviewed by Drummer and Gerostamoulos and will not be discussed in this review. ${ }^{16}$

\section{The body}

Complete information as to the circumstances surrounding death is essential. In some cases, such as suicide by a complex task such as self-hanging, it may be irrelevant to cause of death. However, if an antidepressant or antipsychotic medication is detected, it may be important in ascertaining the mental state of the individual, irrespective of the concentration measured.

Some drugs such as paracetamol and Paraquat will have caused death long after the drug could be detected in samples of blood. ${ }^{17,18}$ Drug screening is an important part of standard protocols for diagnosing brain death, but once the diagnosis has been made, concentrations of drugs such as propoxyphene may rise considerably when respiratory support is maintained but hepatic necrosis is continued. ${ }^{19}$ Bodies are usually stored at $4^{\circ} \mathrm{C}$, and autopsies are usually conducted within a few days of death. Often these ideal conditions are not met with numerous factors coming into play that will have a major effect on the concentrations of drug(s) assayed.

\section{The sample}

Almost all baseline pharmacokinetics and plasma concentration monitoring have been undertaken on plasma samples collected from venous blood. Antemortem samples are extremely important in ascertaining a cause of death but are a rare occurrence outside of hospitals. Forensic samples are usually blood collected from a femoral site, but at times, blood may be collected from central veins, the subclavian vein, or cardiac chambers in cases where femoral samples are unavailable such as in decomposed or burnt bodies. Blind stick collection of femoral samples are probably as reliable as samples obtained from a cut-down and ligated vein, which also allows samples to be collected prior to the formal autopsy. ${ }^{20}$ The use of whole blood complicates the interpretation of some results, where the red blood cell/partition ration is less or greater than one. For example, phenytoin has a partition ratio of $0.5-0.6$, and may in part, account for lower concentrations being found postmortem, while chloroquine concentrations are three to ten times that of plasma due to binding to platelets and granulocytes. ${ }^{21,22}$
Urine samples are easy to collect and contain either parent drug or metabolite(s). Collection of gastric contents will give information and to very recent ingestion of drug, vitreous humor is of particular value in cases involving alcohol, and samples of solid organs such as liver, brain, adipose tissue, hair, and bone may also be collected under special circumstances. To ensure the chemical stability of the drug is maintained, it is essential that correct collection procedures be used for collection, transport, and short- and long-term storage of samples.

Finally, the concentration measured must be as close as possible to the true concentration present at the time of collection. Some drugs such as olanzapine are inherently unstable; hence, concentrations measured will be lowered as time progresses and will underestimate the degree of postmortem redistribution. ${ }^{23}$ In Australia, the Victorian Institute of Forensic Medicine is authorized to obtain femoral blood samples from a body on arrival at the morgue prior to the formal autopsy being undertaken at which time a second femoral sample is collected often days later. In the investigation of antipsychotic drugs in 273 paired blood samples, haloperidol, quetiapine, and risperidone showed little change but up to $112 \%$ increases were found for chlorpromazine and decreases of up to $43 \%$ in the case of $9 \mathrm{OH}$-risperidone. ${ }^{23}$ While plasma samples collected for routine analysis in the clinical situation pose few technical problems, in the forensic area, tissue samples are sometimes obtained from numerous organs. Analytical procedures need to ensure the results have not been altered by matrix effects caused by substances present in the tissue sample and also involve hemolyzed stored blood in the case of valproate..$^{24,25}$

\section{Alterations in concentrations after death}

Multiple biochemical changes such as rapid elevations in potassium to very high concentrations occur in the immediate postmortem period due to failure of the Na ATPase pump before hemolysis occurs. ${ }^{26}$ Oxidative phosphorylation ceases, synthesis of adenosine triphosphate stops, and cellular metabolism changes to anaerobic glycolysis. These result in changes such as lactate levels plateauing at 9 hours, reaching maximal levels at 32-48 hours, and $\mathrm{pH}$ falling to maximal levels at 96 hours. ${ }^{27}$ Details of multiple biochemical changes and their forensic implications, such as the relationship to the time of death and other factors, have been comprehensively reviewed elsewhere. ${ }^{28}$ The conditions of body storage and the time since death are also critical in relation to processes altering the concentrations of drugs. 


\section{Continuing metabolic activities within the body}

Numerous differing processes continue the transformation of drugs within the body after death. Cocaine concentrations will be lowered by continuing spontaneous hydrolysis to benzoylecgonine and also enzymatic conversion to ecgonine methyl ester. Very recent dosing may be determined by the ratio of benzoylecgonine to cocaine in a sample, where a very elevated cocaine concentration and low concentration of benzoylecgonine may represent very recent consumption. ${ }^{29}$

Bacterial invasion of the body commences almost immediately after death and metabolizes numerous sulfur-containing antipsychotics such as chlorpromazine, nitrobenzodiazepines such as clonazepam, and the benzisoxazole derivative risperidone at times, with only metabolites of the parent drugs being detected..$^{30-32}$ Concentrations of physiological compounds such as, for example, gamma-hydroxybutyrate may rise as a result of continuing metabolism. ${ }^{33,34}$ Ethyl alcohol can rise to quite high concentrations as a result of bacterial metabolism, which is of considerable importance in determining the sobriety of the driver of a transport vehicle involved in an accident. In a study of decomposed bodies, Zumwalt et al found concentrations ranged from $10 \mathrm{mg} / \mathrm{dL}$ to $130 \mathrm{mg} / \mathrm{dL}$ in cases where ethyl alcohol was not detected in the vitreous. ${ }^{35}$ Other compounds such as formaldehyde rise in lesser concentrations. The quantitation of nonethanol compounds, such as $n$-propanol, is rarely undertaken but may assist in determining whether ethanol is the result of bacterial synthesis. ${ }^{36}$ Culture of collected samples for bacterial contamination is rarely undertaken in routine forensic work.

\section{Drug diffusion from the gut and other reservoirs}

Drug diffusion from the gut and other reservoirs must be differentiated from diffusion from sites of high drug concentrations such as heart, lung, and liver. These are considered in the area of drug redistribution from sites of high tissue concentrations.

Human cadaveric studies using various concentrations of instilled ethyl alcohol and methanol into the stomach showed time-dependant diffusion into the pericardial fluid and lesser diffusion into the surrounding vessels. The same investigators infused ethanol into the ligated esophagus and found similar aortic blood ethanol concentrations, and so concluded that postmortem esophageal reflux will cause elevations in this area. ${ }^{37}$ Further studies using gastric instillations of amitriptyline, paracetamol, and lithium show extensive diffusion from the stomach and upper small bowel into the base of the left lung, the left lobe of the liver and spleen and less diffusion into the gall bladder, aorta, inferior vena cava, kidneys, and psoas muscles. ${ }^{38}$

Continued absorption of pharmaceutically formulated slow-release drugs would also be expected to occur from more distal areas of the gut well after a dose had been ingested and departed from the stomach. Overdoses of carbamazepine, a drug with profound anticholinergic effects, has slow and erratic absorption with maximal concentrations occurring up to 70 hours after ingestion. In this example, large amounts of drug would remain in the bowel for later local diffusion if death occurs early in the course of an overdose ${ }^{39}$ Unusual cases including high concentrations of drug diffusion from other sites include diphenhydramine and dihydrocodeine diffusing from the bladder to the femoral vein, resulting in higher concentrations than that were found at other sites, ${ }^{40}$ and similar findings were found in fatal cases of intravaginal methamphetamine. ${ }^{41}$

\section{Movement of drugs within the body}

After death, the integrity of cell membranes is lost, and multiple complex processes of drug transport metabolism and storage within vesicles and other structures are destroyed over varying periods of time.

\section{From sites with high organ concentrations}

Drugs vary greatly in their tissue distribution, and many of the published data have been obtained from forensic cases. For example, digoxin is concentrated in myocardium and amitriptyline in liver, resulting in elevated concentrations of these drugs if samples are collected from nearby vessels.

\section{Effect of volume of drug distribution}

Body density is approximately $1 \mathrm{~kg} / \mathrm{L}$, so a uniformly distributed drug will have a volume of drug distribution $(\mathrm{Vd})$ of $70 \mathrm{~L} .{ }^{42}$

Numerous physicochemical factors contribute to a drug's $\mathrm{Vd}$, including its lipid solubility, protein binding in plasma, and its $\mathrm{pKa}$. In addition to these factors, a drug's uptake into and out of tissues is also dependent on numerous transport processes. The hypothesis that postmortem redistribution can be predicted by a drug having a $\mathrm{Vd}$ of $>3 \mathrm{~L} / \mathrm{kg}$ does not hold for all drugs as there are numerous outliers. A similar circumstance applies to prediction in relation to lipid solubility as measured by the octanol/water partition coefficient. ${ }^{42}$

\section{Time durations}

The quantity of drug measured postmortem will not remain the same over time. Movement of morphine from areas 
of high concentration into cardiac blood occurs within minutes after death in rats. ${ }^{43}$ While similar data are of course not available for humans, field samples of cardiac blood showed lower concentrations of amitriptyline, nortriptyline, thioridazine, diphenhydramine, chlorpromazine, doxepin, methadone, ethchlorvynol, pethidine, phentermine, phencyclidine, methamphetamine, and amphetamine than samples collected later at autopsy. ${ }^{7}$ Some drugs have now been shown to have time-related changes occurring in the days after death even allowing for factors such as continuing endogenous and bacterial metabolism and chemical instability. For example, the concentrations of clozapine rose by $>70 \%$ at 4 days and promethazine by $>170 \%$ at 3 days with subsequent falls to low concentrations at 6 days and 5 days, respectively, indicating that there are still a number of unknown and unpredictable factors altering postmortem concentrations. $^{23}$

\section{Markers of postmortem redistribution}

The term redistribution presents a problem as it implies that a drug will disseminate itself within the body without alteration. This is not the case for most drugs or toxic agents. Traditionally, it has been considered that, as a general rule, drugs with a large $\mathrm{Vd}$ are most likely to undergo redistribution because of their wide distribution into body tissues with a figure of 3-4 L/kg being a relative threshold for this to occur, as well as the presence of a high central to peripheral drug ratio. ${ }^{44}$

\section{The ratio of central to peripheral blood concentrations}

The ratio of central to peripheral blood concentrations (C/P ratio) assumes considerable prominence when opinions are given in relation to postmortem drug concentrations. A ratio is often referred to as a means of estimating, or at least deciding, that postmortem assayed result is going to be higher or lower than the antemortem concentration. There are considerable variations in the $\mathrm{C} / \mathrm{P}$ ratio within individual drugs as seen in Table 2. Dalphe-Scott et al published the $\mathrm{C} / \mathrm{P}$ ratios for 113 drugs obtained from 320 cases of which only six (ephedrine, hydrocodone, hydroxyzine, metoprolol, procyclidine, and trifluoperazine) had a maximal $\mathrm{C} / \mathrm{P}$ ratio of 1 or $<1$ and almost all others having values of $>1$ up to a maximal of 21 in the case of diphenhydramine. This indicates that in almost all cases, there will be a difference between central and peripheral samples with the central sample being higher. ${ }^{45}$
Table 2 Central peripheral ratios of some common drugs

\begin{tabular}{lll}
\hline Drug & C/P ratio & Range \\
\hline Amitriptyline & 3.1 & $0.6-15$ \\
Diazepam & 1.6 & $0.2-12$ \\
Chlorpromazine & 4.0 & $1.0-8.0$ \\
Cocaine & 2.3 & $1.5-3.2$ \\
Methadone & 1.8 & $0.4-7.3$ \\
Morphine & 2.2 & $1.0-5.8$ \\
Propoxyphene & 2.6 & $0.8-12$ \\
\hline
\end{tabular}

Note: Data from Baselt."

Abbreviation: C/P, central to peripheral blood concentrations.

The central component is more easily understood as there are often large reservoirs of drug in lung, liver, heart, or gastrointestinal tract, so diffusion across concentration gradients raises concentrations in central veins. The peripheral component relies on transport out of striated muscle, connective and adipose tissues. When factors such as chemical instability and bacterial invasion as discussed previously are excluded, the P part of the ratio assumes that the venous site has only received redistributed blood from surrounding tissue, largely striated muscle, in the thigh or less frequently upper arm. A number of factors determine the peripheral component of the $\mathrm{C} / \mathrm{P}$ ratio, including the postmortem circulation of blood, and transport in and out of myocytes and other tissues, as well as the time over which the drug had been administered. While there are exceptions to this assumption, such as the case of diffusion of dihydrocodeine from the bladder, such cases are very unusual. ${ }^{40}$

\section{Postmortem blood circulation}

Body movement after death, prolonged cardiopulmonary resuscitation, and changes caused by advanced putrefaction may result in movement from areas of high central concentration to the peripheral sites of sampling. ${ }^{?}$

\section{Drug uptake processes}

Drug uptake into muscle is very complex and depends on numerous transport systems. For example, among the most studied group of drugs in relation to muscle are the lipidlowering HMG-CoA inhibiting statins, atorvastatin, and rosuvastatin. The muscle concentration is dependent on uptake by OATP2B1 (human organic anion transporting polypeptide 2B1) and efflux transporters MRP1, MRP4, and MRP5. These systems are subject to the interacting effects of co-administered drugs, as well as genetic polymorphism. ${ }^{46}$

Assuming that redistribution will occur across a concentration gradient when transporting systems cease to function after death, there will be differing muscle concentrations between patients if the transporting systems were altered by interacting 
drugs before death. The concentration in muscle, and hence, the $\mathrm{C} / \mathrm{P}$ ratio will also depend on the duration of therapy and individual differences in cellular uptake. While the myotoxicity of statins has been the subject of intensive research, there are at present no available data on the postmortem $\mathrm{C} / \mathrm{P}$ ratios of statins. ${ }^{11}$

\section{Duration of therapy}

Maximal drug distribution throughout the body will occur after approximately four to five half-lives when a drug has reached a pharmacokinetic steady state. If a steady state has not been reached, then there may be considerably less drug to redistribute from peripheral tissues into venous blood. Unfortunately, the duration of drug therapy is often unknown in many forensic cases. This factor probably accounts for some of the wide spread of central to peripheral ratios for individual drugs found in tables and reference books. Time intervals are therefore critical for any meaningful interpretation of a $\mathrm{C} / \mathrm{P}$ ratio. Consider the theoretical case of a sudden death resulting from a sudden cardiac arrest occurring within minutes of the administration of the now very commonly used cardiostimulant drug methamphetamine. The offending drug will not have equilibrated with peripheral or probably cardiac tissue, so the C/P ratio should be approximately 1 . From a series of 20 methamphetamine caused and associated methamphetamine deaths, peripheral methamphetamine concentrations ranged being $0.3-4.10 \mu \mathrm{g} / \mathrm{mL}$, central blood from $0.04 \mu \mathrm{g} / \mathrm{mL}$ to $8.95 \mu \mathrm{g} / \mathrm{mL}$, and $\mathrm{C} / \mathrm{P}$ ratios from 1.3 to 5.0. ${ }^{47}$ Unfortunately, the times of death were not individualized but varied between 12 hours and 36 hours. When cardiac blood has been collected "in the field" by cardiac puncture prior to autopsy, methamphetamine concentrations have been reported to rise by a factor of up to 2.4 times by the time of autopsy, though in the same publication, there is one case of a methamphetamine-associated death due to trauma where the heart/femoral ratio at autopsy was $1.0 .^{7}$ It can be concluded that there is considerable variation in $\mathrm{C} / \mathrm{P}$ ratios, and central (cardiac) blood increases with time after death.

Expert opinions are often requested in cases of methamphetamine-associated deaths. From these data, it can be concluded that the cases with lower ratios probably had shorter time intervals after death. It would not be possible to accurately determine the blood concentration in an individual case from a peripheral sample at the time of death. Consider the case of a sudden cardiac-related death occurring shortly after taking methamphetamine. If there is no evidence of intercurrent pathology and methamphetamine is detected in a sample of peripheral blood, then methamphetamine can be considered to be the triggering agent, irrespective of the measured concentration.

\section{Newer approaches to predicting drug redistribution}

Alterations in blood/liver concentration ratios were considered a possible means of determining the time of death with a liver/blood ratio of $>4$ indicating death occurred within 5 hours of ingestion. Curry and Sunshine were unable to confirm this hypothesis when they reviewed 52 cases, where the time of death was known. Their work has been a stimulus to investigate mechanisms for determining alterations in postmortem drug concentrations. ${ }^{48}$

Investigations undertaken by Vorpahl and Coe in 1978 showed increases in digoxin concentrations after death. ${ }^{49}$ In 1990, Pounder and Jones reported the differing tissue concentrations of doxepin, desmethyldoxepin, three barbiturates, clomipramine, desmethylclomipramine, imipramine, desipramine, and flurazepam. Their assessment of redistribution of drugs after death has been called a "toxicological nightmare". ${ }^{15}$ Langford and Pounder later undertook a very detailed biochemical and toxicological examination of a single case of a female aged 34 who died as a result of an overdose of amitriptyline. In this investigation report, they measured numerous hepatic enzymes, bilirubin, creatine kinase amino acids, glucose, and lactic acid, as well as concentrations of amitriptyline and nortriptyline from 19 blood samples collected from various central and peripheral sites, fluid samples from vitreous, pericardium, bile, ascitic fluid, urine, stomach, and duodenal contents, and solid organ samples from both lobes of the liver, apex and posterobasal lung, right dome of the diaphragm, left and right rectus abdominus, and right gastrocnemius muscle.

Concentrations of amitriptyline ranged from $42.1 \mu \mathrm{g} / \mathrm{mL}$ in bile to $1.8 \mu \mathrm{g} / \mathrm{mL}$ in femoral blood. While there were correlations between concentrations of the aminoacids, glycine, leucine, methionine, and serine and valine with blood concentrations, hepatic enzymes were poorly correlated with drug concentrations. The authors concluded that amino acids, and particularly, methionine may be useful as marker of pulmonary drug redistribution. ${ }^{50}$ More recently, McIntyre conducted a comprehensive review from the published literature of 13 drug concentrations (tramadol, carisoprodol, venlafaxine, mirtazapine, methadone, lamotrigine, quetiapine, citalopram, paroxetine, olanzapine, amitriptyline, clomipramine, and sertraline) measured at various sites and reported by various laboratories. ${ }^{51}$ Allowing for these difficulties, he concluded that a liver/peripheral blood ratio of $<5$ means that there is little 
propensity to postmortem redistribution and if $>20-30$ redistribution was likely to take place. The same author has further expanded this hypothesis to include an "F" factor (antemortem concentration $=$ postmortem concentration $/ F$ ) as a means of identifying drug redistribution. ${ }^{52}$ Application of this factor will require the acquisition of a larger database than is available at present, particularly as measurement of liver concentrations is not without difficulties such as matrix effects. It is also not measured as a routine test in many laboratories.

The application of advanced computer modeling using quantitative structure-activity relationship methodology has been applied to predict the potential for drugs to undergo postmortem redistribution. At present, it has had limited success, but this approach may have potential in the future. ${ }^{53}$

\section{Conclusion}

Passive diffusion from sites of high concentration such as the intestinal tract and liver is easily understood, but the biochemistry causing other changes is clearly more complex. It is less individually predictable on the basis of $\mathrm{Vd}$, lipid solubility, $\mathrm{pKa}$, protein binding, and $\mathrm{C} / \mathrm{P}$ ratio than was previously thought. The widely used $\mathrm{C} / \mathrm{P}$ ratio shows considerable alterations after death with few drugs having a ratio of 1.0 or $<1.0$. Accurate interpretation is possible only when the time of death is known. Prolonged cardiopulmonary resuscitation may complicate the issue by transporting drugs in central areas to the peripheral veins. There is at present no definite marker to predict whether or by how much drug will undergo postmortem redistribution. The recent liver/peripheral blood ratio study serves as a guide for further research. When interpreting the results of drug concentrations after death, it remains essential to have a complete knowledge of the case and to review the known data available on the particular drug.

\section{Disclosure}

The author has provided expert evidence in numerous forensic cases. He has no conflicts of interest relevant to this work.

\section{References}

1. Wharton JC. The Arsenic Century: How Victorian Britain was Poisoned at Home, Work and Play. Oxford University Press Inc, New York, 2010.

2. Brown L, Stewart CG. Trial of Dr Pritchard. In: Brown L, Stewart GG, editors. Trials of Murder by Poisoning. London: Stevens and Sons 119 Chancery Lane Law Publishers and Booksellers; 1883:397-448.

3. Mc Bay J. Toxocological findings in fatal poisonings. Clin Chem. 1973;19:361-365.

4. Pounder DJ. The case of Dr Shipman. Am J Forensic Med Pathol. 2003;24: 219-226.

5. Drummer O, Forrest ARW, Goldberger B, Karch SB. Forensic science in the dock. Br Med J. 2004;329:636-637.
6. Kennedy MC. Postmortem drug concentrations. Intern Med J. 2010;40:183-187.

7. Prouty RW, Anderson WH. The forensic science implications of site and temporal influences on post-mortem blood-drug concentrations. J Forensic Sci. 1990;35:243-270.

8. Druid H, Holmgren P. A compilation of fatal and control concentrations of drugs in postmortem femoral blood. J Forensic Sci. 1997;42: 79-87.

9. Schulz M, Iweresen-Bergmann S, Andresen H, Schmoldt A. Therapeutic and toxic blood concentrations of nearly 1000 drugs and other xenobiotics. Crit Care. 2012;16:R136.

10. Jones AW, Holmgren A. Concentration distributions of the drugs most frequently identified in post-mortem femoral blood representing all causes of death. Med Sci Law. 2009;49:257-273.

11. Baselt R (ed.). Disposition of Toxic Drugs and Chemicals in Man. 10th ed. Biomedical Publications, Seal Beach, California (USA), 2014.

12. Repetto MR, Repetto M. Habitual, toxic and lethal concentrations of 103 drugs of abuse in humans. Clin Toxicol. 1997;35:1-9.

13. BaileyDN, Shaw RF. Interpretation ofblood and tissue concentrations infatal self-ingested overdose involving amitriptyline: an update (1978-1979). J Anal Toxicol. 1980;4:232-236.

14. Jones RJ, Pounder D. Site dependence of drug concentrations in postmortem blood - a case study. J Anal Toxicol. 1987;11:186-190.

15. Pounder DJ, Jones GA. Post-mortem drug redistribution - a toxicological nightmare. Forensic Sci Int. 1990;45:253-263.

16. Drummer $\mathrm{OH}$, Gerostamoulos D. Postmortem drug analysis: analytical and toxicological aspects. Ther Drug Monit. 2002;24:199-209.

17. Ferner RE, Dear JW, Bateman DN. Management of paracetamol poisoning. Br Med J. 2011;342:968-972.

18. Conradi SE, Olanoff LS, Dawson J. Fatality due to paraquat intoxication: confirmed by postmortem tissue analysis. Am J Clin Pathol. 1983;80: 771-776.

19. Bednareczyk LR, Wetli CV, Balkon J. Respiratory toxicology. J Forensic Sci. 1981;26:373-380.

20. Hargrove VM, McCutcheon JR. Comparison of drug concentrations taken from clamped and unclamped vessels. J Anal Toxicol. 2008;32: 621-625.

21. May T, Jurgens U, Rambrek B, Schnabel R. Comparison between premortem and postmortem serum concentrations of phenobarbital, phenytoin, carbamazepine and its 10,11-epoxide metabolite in institutionalised patients with epilepsy. Epilepsy Res. 1999;33:57-65.

22. White NJ. Clinical pharmacokinetics of anti-malarial drugs. Clin Pharmacokinet. 1985;10:187-215.

23. Sarr E, Beyer J, Gerostamoulos D, Drummer OH. The time-dependant post-mortem redistribution of antipsychotic drugs. Forensic Sci Int. 2012;222:223-227.

24. Taylor PJ. Matrix effects: the Achilles heel of high-performance liquid chromatography electrospray-tandem mass spectroscopy. Clin Biochem. 2005;38:328-334.

25. Kiencke V, Andreson-Streichert H, Muller A, Iwersen-Bergmann S. Quantitative determination of valproic acid in postmortem blood samples - evidence of strong matrix dependency and instability. Int $J$ Legal Med. 2013;127:1101-1107.

26. Jetter WW. Postmortem biochemical changes. J Forensic Sci. 1959;4: $330-341$.

27. Donaldson AE, Lamont IL. Biochemistry changes that occur after death: potential markers for determining post-mortem interval. PLoS One. 2013;8(11):e2011.

28. Coe JI. Postmortem chemistry update. Am J Forensic Med Pathol. 1993;14: 91-117.

29. Mc Kinney PE, Phillips S, Gomez HF, Brent J, Mac Intyre M, Watson A. Vitreous humor cocaine and metabolite concentrations: do postmortem specimens reflect blood levels at the time of death? J Forensic Sci. 1995;40:102-107.

30. Batziris HP, Mc Intyre IM, Drummer OH. The effect of sulphurmetabolising bacteria on sulphur-containing psychotropic drugs. Int Biodeterior Biodegradation. 1999;44:111-116. 
31. Robertson MD, Drummer OH. Postmortem drug metabolism by bacteria. J Forensic Sci. 1995;40:382-386.

32. Taylor K, Elliott K. An unusual case of risperidone instability in a fatality presenting an analytical and interpretative challenge. Drug Test Anal. 2013;5:748-752.

33. Kintz P, Villain C, Bertrand L. GHB in postmortem toxicology: discrimination between endogenous production from exposure using multiple specimens. Forensic Sci Int. 2004;143:177-181.

34. Sakurada K, Kobayshi M, Iwase H, et al. Production of gammagutyric acid in postmortem liver increases with time after death. Toxicol Lett. 2002;129:207-217.

35. Zumwalt RE, Bost RO, Sunshine I. Evaluation of ethanol concentrations in decomposed bodies. J Forensic Sci. 1982;27:549-554.

36. O'Neal C, Polkis A. Postmortem production of ethanol and factors that influence interpretation. A critical review. Am J Forensic Med Pathol. 1996; 17:8-20.

37. Pounder DJ, Smith DRW. Postmortem diffusion of alcohol from the stomach. Am J Forensic Med Pathol. 1995;16:89-96.

38. Pounder D, Fuke C, Cox D, Smith D, Kuroda N. Postmortem diffusion of drugs from gastric residue: an experimental study. Am J Forensic Med Pathol. 1996;17:1-7.

39. Spiller HA. Management of carbamazepine overdose. Pediatr Emerg Care. 2001;17:452-456

40. Moriya F, Hashomoto Y. Postmortem diffusion of drug from the bladder into femoral venous blood. Forensic Sci Int. 2001;123:248-253.

41. Jones P, Mutsungamar P, Prahlow JA. Accidental death via intravaginal absorption of methamphetamine. Forensic Sci Med Pathol. 2014;10: 234-248.

42. Ferner RE. Post-mortem clinical pharmacology. Br J Clin Pharmacol. 2008;66:430-443.
43. Sawyer WR, Forney RB. Post mortem distribution of morphine in rats. Forensic Sci Int. 1988;38:259-273.

44. Pelisser-Alicott A-L, Gaulier J-M, Champsaur P, Marquet P. Mechanisms underlying postmortem redistribution of drugs: a review. JAnal Toxicol. 2003;27:533-544.

45. Dalpe-Scott M, Degouffe M, Garbutt D, Drost M. A comparison of drug concentrations in postmortem cardiac and peripheral blood in 320 cases. Can Soc Forensic Sci J. 1995;28:113-121.

46. Knauer MJ, Urquhart BL, Meyer zu Schwabedissen HE, et al. Human skeletal muscle drug transporters determine local exposure and toxicity of statins. Circ Res. 2010;106:297-306.

47. Barnhart FE, Fogacci JR, Reed DW. Methamphetamine - a study of postmortem redistribution. J Anal Toxicol. 1999;23:69-70.

48. Curry AS, Sunshine I. The liver: blood ratio in cases of barbiturate poisoning. Toxicol Appl Pharmacol. 1960;2:602-606.

49. Vorpahl TE, Coe JL. Correlation of antemortem and postmortem digoxin levels. J Forensic Sci. 1978;2:329-334.

50. Langford AM, Pounder DJ. Possible markers for postmortem drug redistribution. J Forensic Sci. 1997;42:88-92.

51. McIntyre IM. Liver and peripheral blood concentration ratio $(\mathrm{L} / \mathrm{P})$ as a marker of postmortem drug redistribution: a literature review. Forensic Sci Med Pathol. 2014;10:91-96.

52. Mc Intyre IM. Identification of a postmortem redistribution factor (F) for forensic toxicology. J Anal Sci Technol. 2014;5:24.

53. Giaginis C, Tsantili-Kakoulidou A, Theocharis S. Quantative structureactivity relationship (QSAR) methodology in forensic toxicology: modeling postmortem redistribution of structurally diverse drugs using multivariate statistics. Forensic Sci Int. 2009;180:9-15.
Pathology and Laboratory Medicine International

\section{Publish your work in this journal}

Pathology and Laboratory Medicine International is a peer-reviewed, open access journal focusing on innovative basic research and translational research related to pathology or human disease. The journal includes original research, updates, case reports, reviews and commentaries on current controversies. The Academic Sponsor

\section{Dovepress}

of this journal is the Chinese American Pathology Association (CAPA). The manuscript management system is completely online and includes a very quick and fair peer-review system. Visit http://www.dovepress.com/testimonials.php to read real quotes from published authors. 